\section{REPARACION DE UN DIQUE SECO EN EL FERROL/ESPAÑA}

\author{
Mariano Navas Gutiérrez, \\ Ingeniero de Caminos \\ Mariano Blanco González, \\ Ingeniero Naval \\ $553-10$
}

\section{SINOPSIS}

El dique seco de El Ferrol, construido como dique de gravedad según la técnica de la época (1913), ha sufrido una serie de averías como consecuencia de su envejecimiento, que ha obligado a emprender una obra de reparación según las modernas técnicas de soleras ancladas y drenadas, y pantallas de bentonita-cemento.

Se ha construido una losa de $30 \mathrm{~cm}$ en el antedique, anclada con armaduras activas, formado cada anclaje por diez cables según una malla de $3 \times 3 \mathrm{~m}$.

Para aliviar la subpresión se ha colocado un dren entre la solera permeable actualmente existente y la losa.

Con la pantalla de bentonita-cemento se pretende cerrar la entrada de agua por el relleno permeable del antiguo dique. El terreno natural es prácticamente impermeable.

\section{INTRODUCCION}

EI Dique Seco n. ${ }^{\circ} 2$ de El Ferrol fue construido en el año 1913, según proyecto de la Casa "Sir John Jackson Ltd.", para la reparación de buques de 20.000 a 24.000 t de desplazamiento, con un presupuesto de 6.766.600 Ptas., en el que se incluía el vaso del dique y otras obras anejas (casa de bombas, talleres, etc.)

Su emplazamiento está situado entre otros dos diques construidos en la época de Fernando VI y Carlos III, los cuales quedaron fuera de servicio

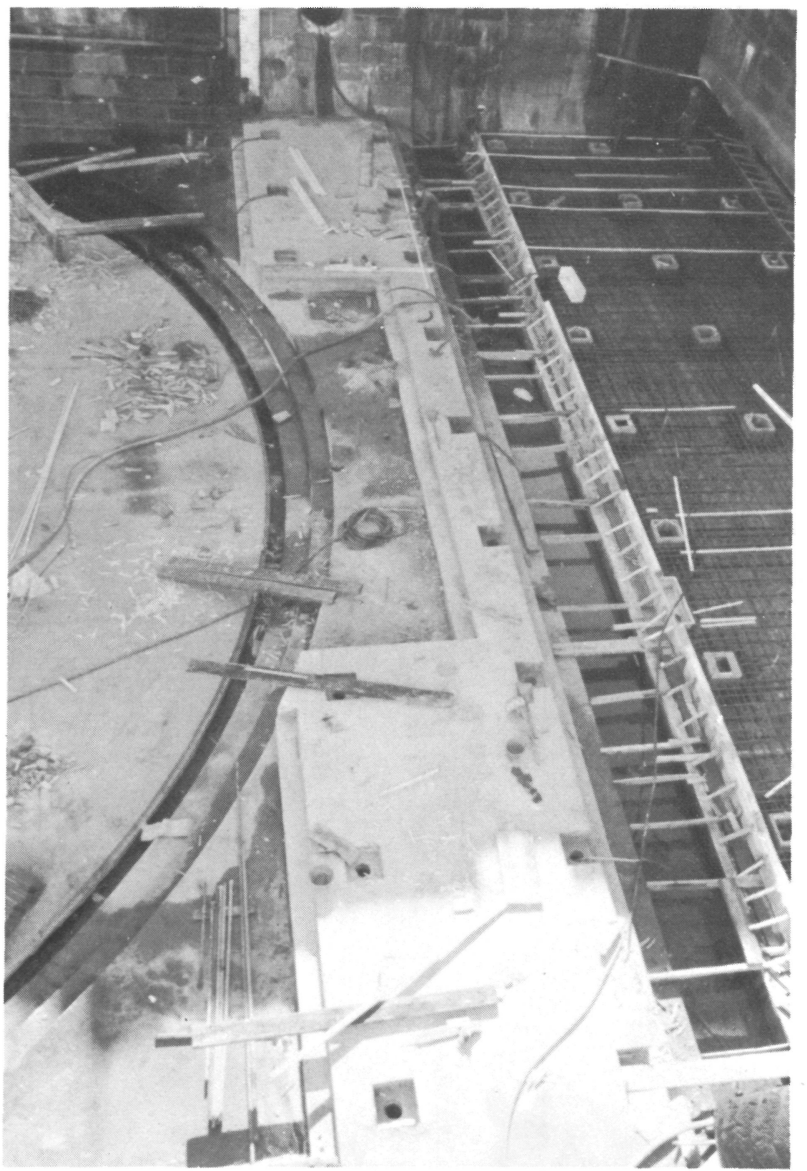

tras la construcción de aquél. El antiguo dique a estribor del actual, se cerró con un muro de hormigón revestido de sillería de granito, y el de babor con un muro de mampostería de mortero hidráulico revestido también de sillería. Ambos se usaron como vertederos de las tierras excavadas en la construcción del nuevo dique seco.

El dique en cuestión, de planta rectangular, tenía una eslora en el zampeado desde la primera ranura hasta proa, de $174,75 \mathrm{~m}$, y la longitud del antedique a partir de la dársena, es de $23 \mathrm{~m}$. La manga en el plan del dique es de $21 \mathrm{~m}$, y en el antedique, de $31 \mathrm{~m}$. El calado de pleamar de mareas vivas ordinarias es de $12,45 \mathrm{~m}$. Posteriormente, en 1927, se aumentó la eslora por proa, dándole la forma trapecial actual (figura 1), pasando a tener $212 \mathrm{~m}$ de eslora.

La sección transversal del dique tiene la forma clásica de la época, con intradós a base de mese- 


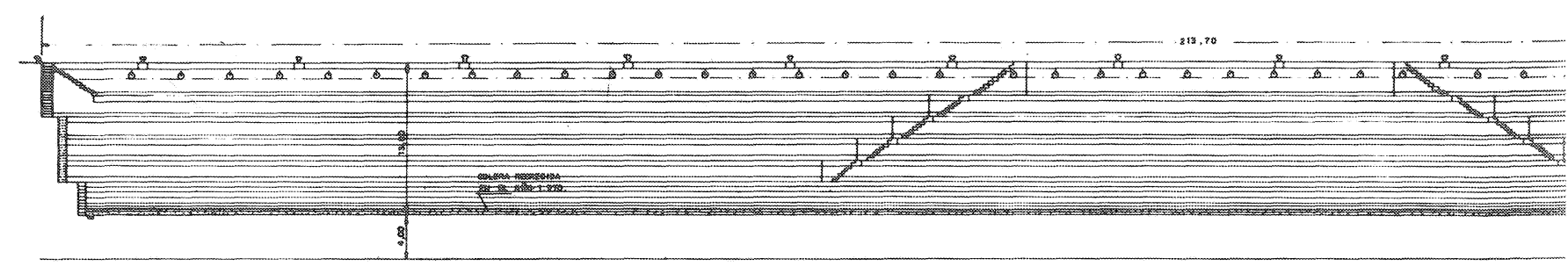

seccion Losernuanal

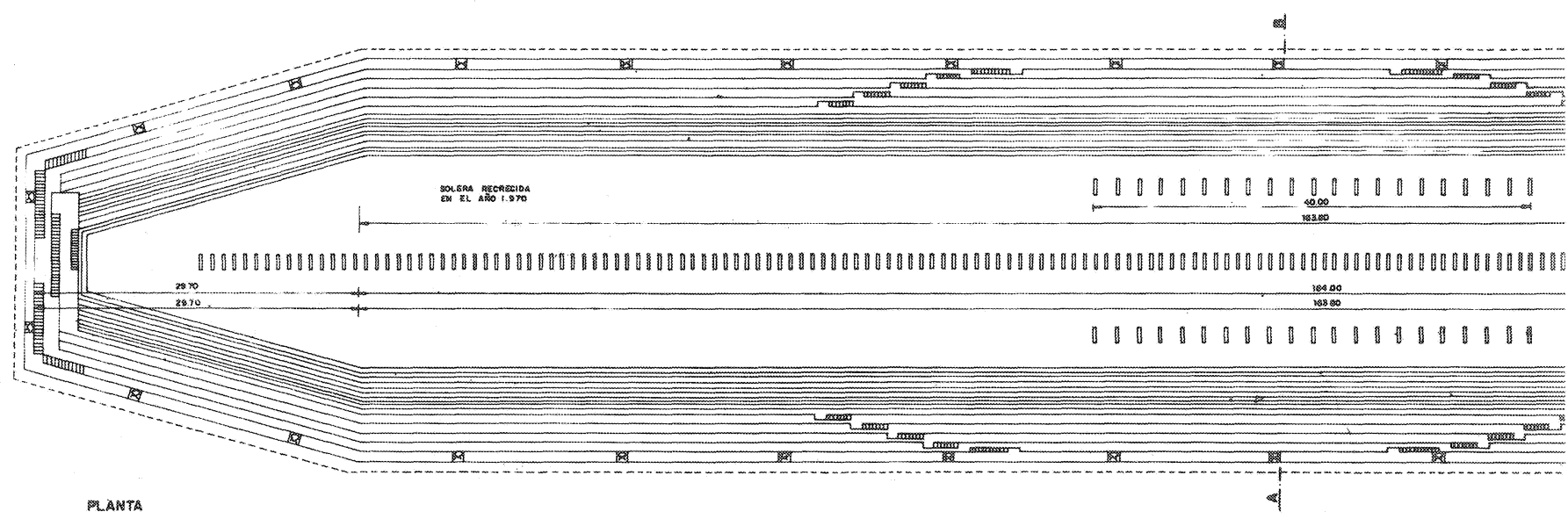

Fig. 1. Sección longitudinal y planta
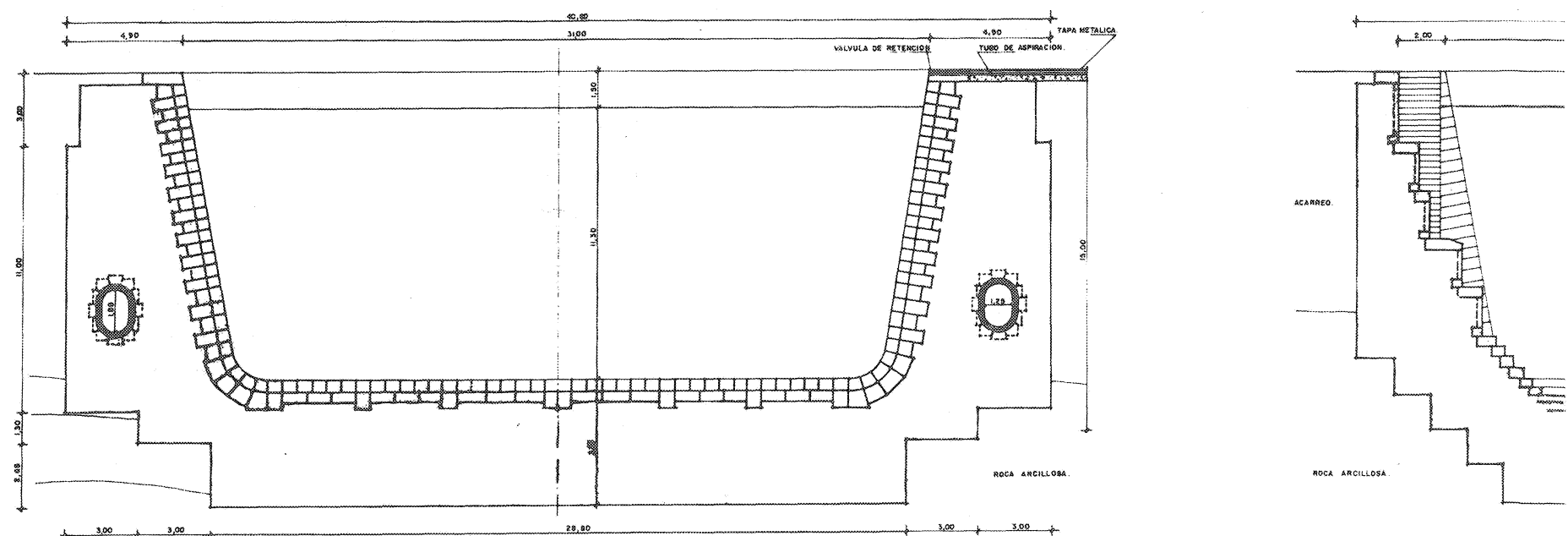

$\sec \sin \sin$

Fig. 2. y b. Secciones transversales (cajero y batientes) 

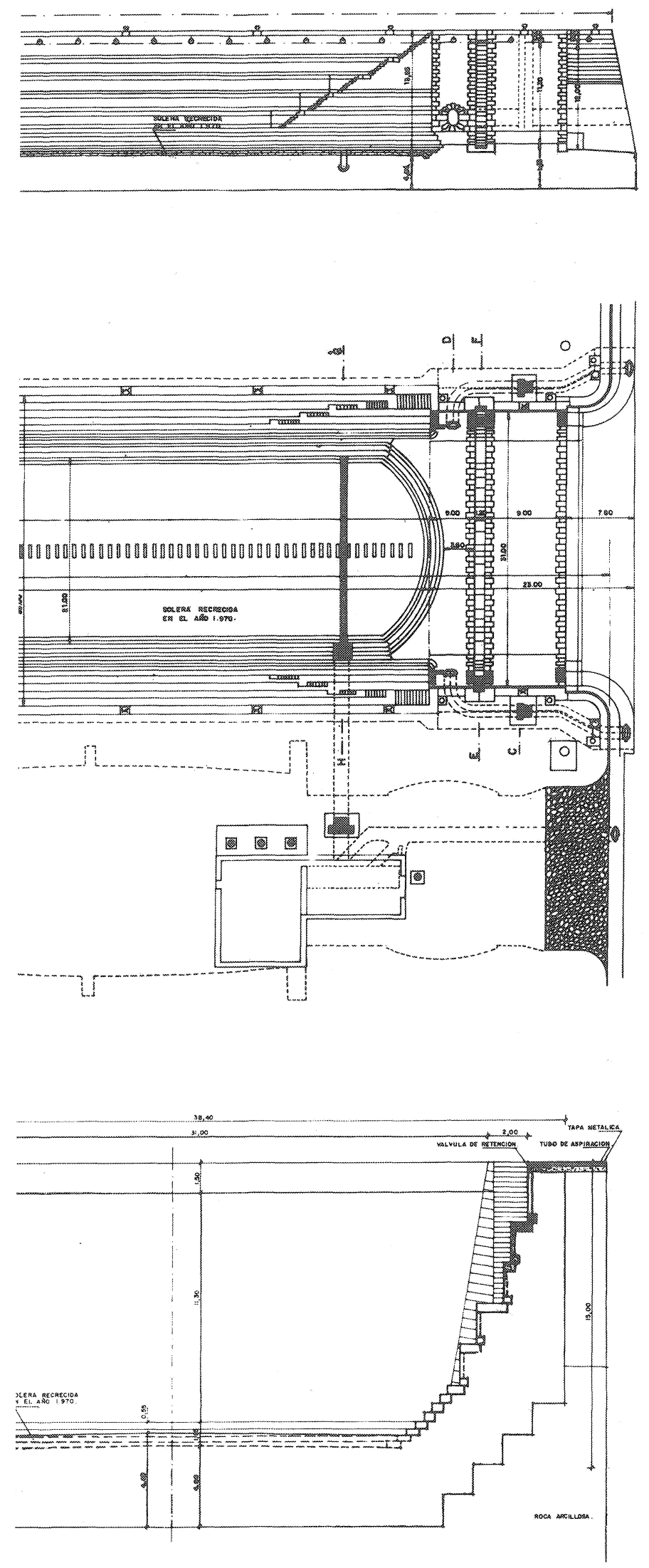

b tas horizontales o altares, salvo en el antedique, formado por batientes planos (figura 2). La tipolo gía estructural corresponde a la de un dique de gravedad que trabaja como bóveda invertida, pero con la singularidad de que los cimientos de los cajeros están por encima de la solera como si se tratase de un importante revestimiento del vaso excavado.

En su construcción se empleó hormigón ciclópeo, cuya puesta en obra dejó mucho que desear, 10 cual es normal dada la poca experiencia que se tenia en aquella época en este tipo de trabajos.

\section{AVERIAS Y PROPUESTAS DE SOLUCIONES}

La biografía de reparaciones del dique, que fue el mayor de España durante muchos años, ha sido muy extensa.

La primera reparación a destacar se hizo en 1952, al aparecer en la solera del antedique unas grietas que se temió pudieran dar lugar a un levanta. miento general del plan por subpresión u otras causas, poniendo en peligro la estabilidad del barm co-puerta.

Los reconocimientos geotécnicos demostraron que la solera descansaba sobre unas pizarrasmarcilla sas hidratadas, conocidas localmente como "pena mortan, prácticamente impermeables. El hormigón tenia signos de descomposición que se estimaron análogos a los producidos por el agua del mar sobre un cemento con gran proporción de magnesia, lo que provoca - como es sabido- un aumento considerable de volumen. Por otro lado, se observaron que las zonas descompuestas aparecian distribuidas en superilicies sensiblemente ho rizontales, y que probablemente se correspondian con juntas de construcción, las cuales dieron lugar a las vias de agua que provocaron el agrietamiento de las tongadas superiores.

Con tal diagnóstico, el proyecto de reparación consistió en una campaña de inyecciones a base de cemento puzolánico para restaurar las condiciones de impermeabilidad de la masa de hormigón, completado con un bulonado vertical de cosido. Dicha obra de reparación, de bajo coste, fue suficientemente eficaz, ya que no existió ninguna otra en la solera durante bastantes años.

Con posterioridad fue preciso realizar diversas campañas de inyecciones de cemento en los cajo ros del dique, sin demasiado éxito.

Recientemente, han aparecido una serie de averias que, en resumen, consisten en un agrietamiento de la solera del antedique de aspecto análogo al detectado en 1952; el agrietamiento del batiente de babor con rezume de agua y el abombamiento del paramento en el cajero de babor a mitad de la eslora, en una zona de $2 \mathrm{~m}^{2}$, aproximadamente, 


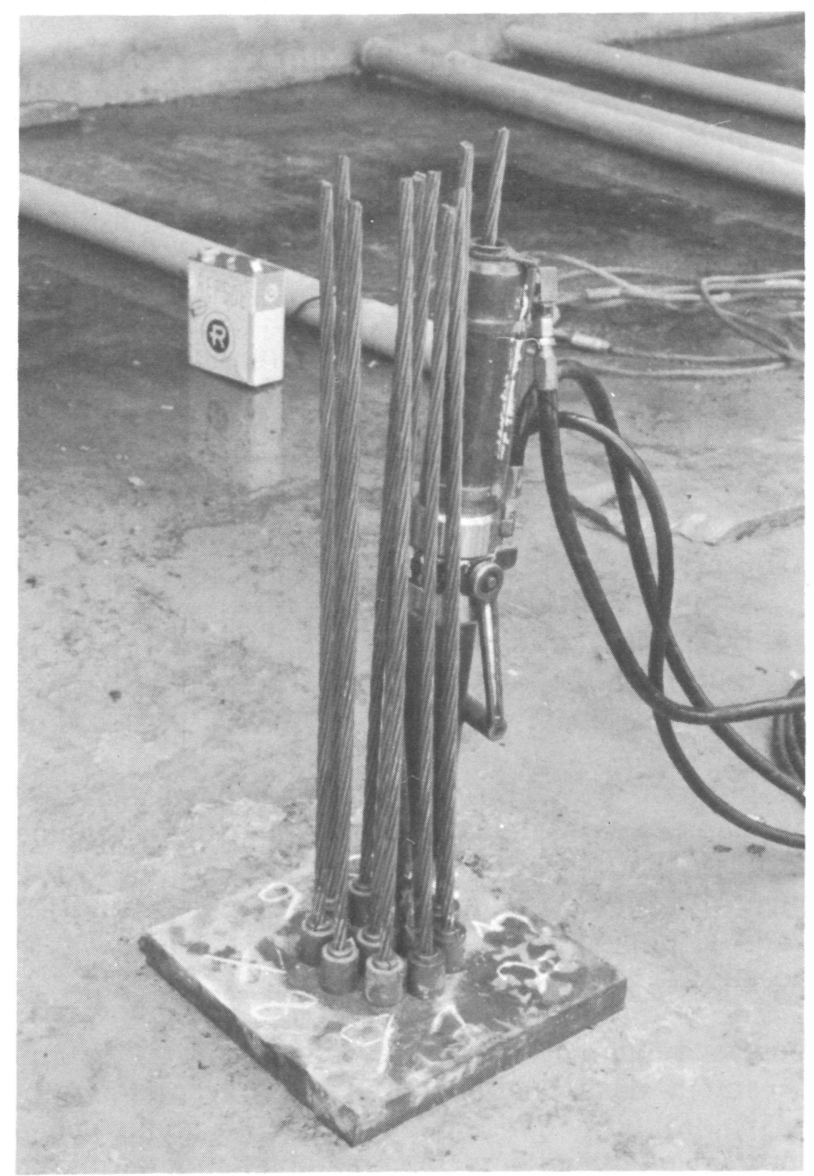

con incluso desprendimiento de trozos de hormigón.

Ante el peligro que dichas averias pudieran suponer para la estabilidad de la obra, se han barajado una serie de soluciones que van desde la demolición de todo el antedique y su reconstrucción al abrigo de una ataguía, o la construcción de un antedique adosado al actual con la técnica de cajones flotantes, etc., hasta la disminución de la eslora del dique a costa de dejar fuera de servicio la ranura exterior, y con ello toda la zona que presenta mayor peligro potencial.

La relación del coste estimado entre las distintas soluciones presentadas, sin disminución de eslo ra, varía de 1 a 20 .

La toma de decisión de la solución a adoptar, sobre la base de su viabilidad técnica, planteó un problema en el que -como tantas veces ocurre en ingenieria - se hubieron de conjugar criterios técnicos, económicos, funcionales, etc. A tal fin, fue necesario realizar un análisis coste/eficacia en el que se computaron las ventajas e inconvenientes de cada solución, para obtener - supuesto establecido una escala de preferencias - un indicador que permitiera elegir la solución más adecuada a dicha escala de preferencias y/o requerimientos preestablecidos por la Propiedad.

\section{SOLUCION ADOPTADA}

Un proyecto de reparación de este tipo exige el conocimiento de las causas que han provocado las averías, pues no se trata de reparar sus efectos solamente, sino también de intentar atajarlas definitivamente.

De los reconocimientos y sondeos realizados se ha podido deducir que nos encontramos con un hormigón muy poroso y, por consiguiente, muy susceptible de ser atacado por agentes químicos; asimismo, se ha puesto de manifiesto que las zonas de relleno del antiguo dique a babor del actual, circula agua que se puede clasificar como fuertemente agresivo, y que sigue con fidelidad la carrera de marcas. La permeabilidad de dicho reIleno disminuye rápidamente con la eslora, así pues, los abombamientos y desprendimientos lo calizados en el paramento del cajero de babor, suficientemente alejado del antedique, se explican como consecuencia del empuje de aguas vagabundas - procedentes de la rotura de un colector próximo- sobre el paramento superficial mucho más impermeable que la masa de hormigón. Los testigos de hormigón extraidos en cajeros, batientes y solera, han demostrado que el hormigón se puede considerar bastante aceptable, aunque poroso, y que dista de la ruina.

A la luz de dichas conclusiones, con el proyecto de solución que se ha redactado, se pretendia por un lado impermeabilizar la masa de hormigón, y por otro, alejar el agente causante del deterioro del mismo.

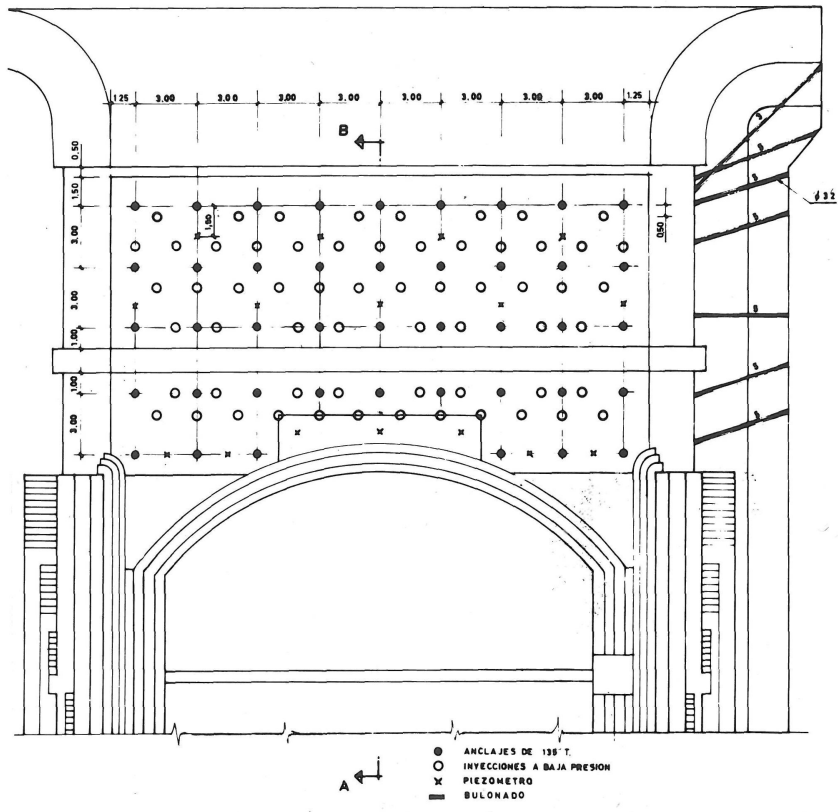

Fig. 3 Planta del antedique. Inyecciones y anclajes 
En la 1. " fase del proyecto, se previa realizar una campaña de inyecciones de cemento, según una malla más o menos regular (ver figura 3), y, apro. vechando la experiencia adquirida en los últimos diques de solera anclada, la construcción de una losa armada de $30 \mathrm{~cm}$, anclada con armaduras activas al terreno rocoso, capaz de resistir toda la subpresión en su cara inferior (figura 3).

Entre la solera actual y la losu anclada, se ha colocado un dren de grava, cuya misión será la de aliviar, en su caso, la subpresión que pueda producirse en la cara inferior de la losa (figura 4).

Esta solución de losa anclada muy delgada, que complementa a la solera actual, tiene antecedentes en una técnica suficientemente sancionada por la experiencia en diques secos, tales como en Trieste, Alejandría, Scaramagna, Emden, etc., en que, para contrarrestar la subpresión, se contó con el bulbo movilizado por el anclaje.

Esta primera fase se complementa con un bulonado del batiente de babor e inyección del mismo con lechada de cemento.

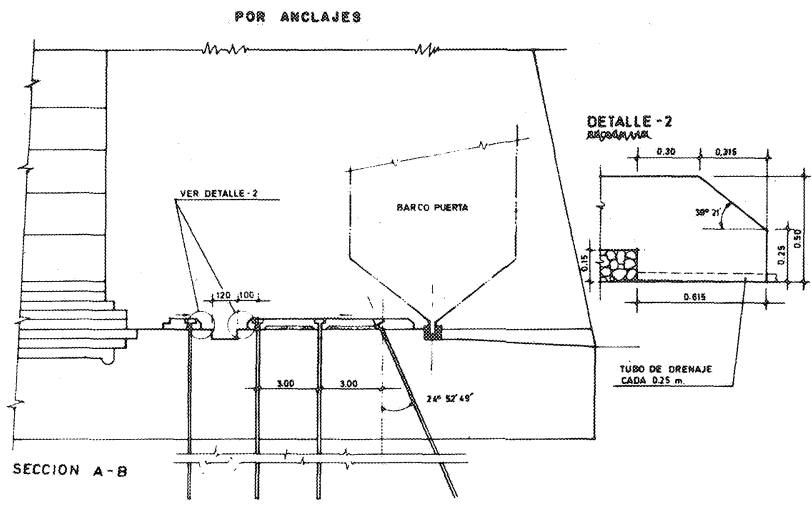

Fig. 4 Alzado antedique. Anclajes y drenajes

Cada anclaje está formado por diez cables del tipo $1 \times 7+0$, por siete alambres de $5 \mathrm{~mm}$ y 180 kilogramos por milimetro cuadrado de límite elástico, según una malla de $3 \times 3 \mathrm{~m}$. La capacidad del anclaje es de $130 \mathrm{t}$ (ver figura 5). Se ha considerado necesario un bulbo de adherencia de 5 metros.

Tanto en solera como en batientes, la inyección ha de ser a baja presión.

En la segunda fase se prevé la construcción de una pantalla de bentonita-cemento en $L$, que cierra el acceso de agua por el relleno del antiguo dique, y protege el batiente de babor del antedique (figura 6).

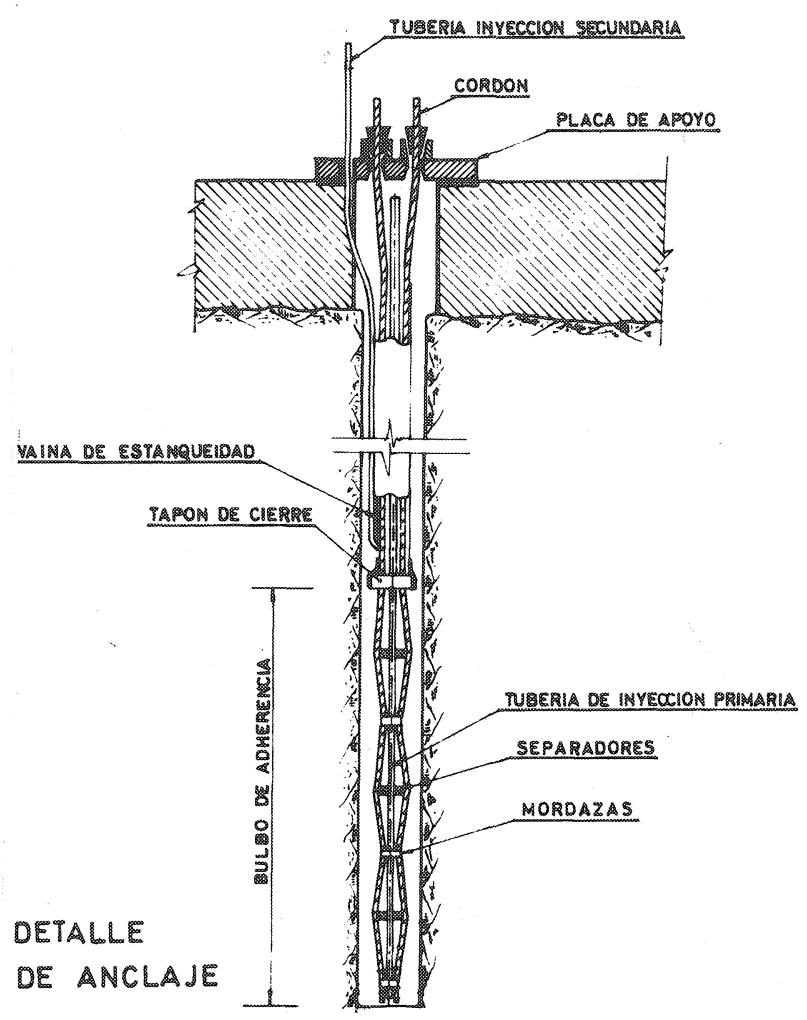

Fig. 5 Detalle del anclaje

La pantalla de bentonita-cemento va a tener un espesor de $80 \mathrm{~cm}$, y se ha de realizar por paños alternando con cuchara guiada tipo "Kelly Caldwell.. Como es normal en este tipo de trabajos, se prevé la construcción de unas vigas de guiado de la cuchara, durante la construcción de la pantalla. Con la utilización de los lodos trixotrópicos, es posible construirlo manteniendo estables las paredes mientras se ejecuta la excavación, y con la adición de una dosis de cemento $\left(300 \mathrm{~kg} / \mathrm{m}^{3}\right)$ se consigue darie cierta resistencia manteniendo la condición fundamental de impermeabilización que se persigue.

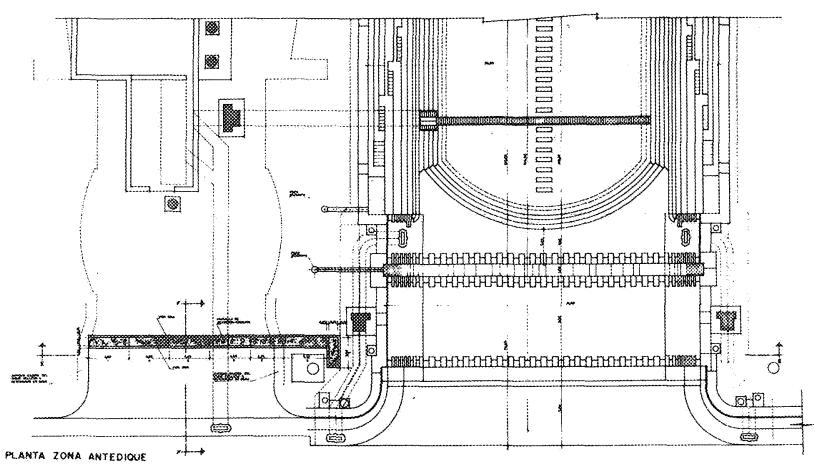

Fig. 6 Pantalla bentonita-cemento 


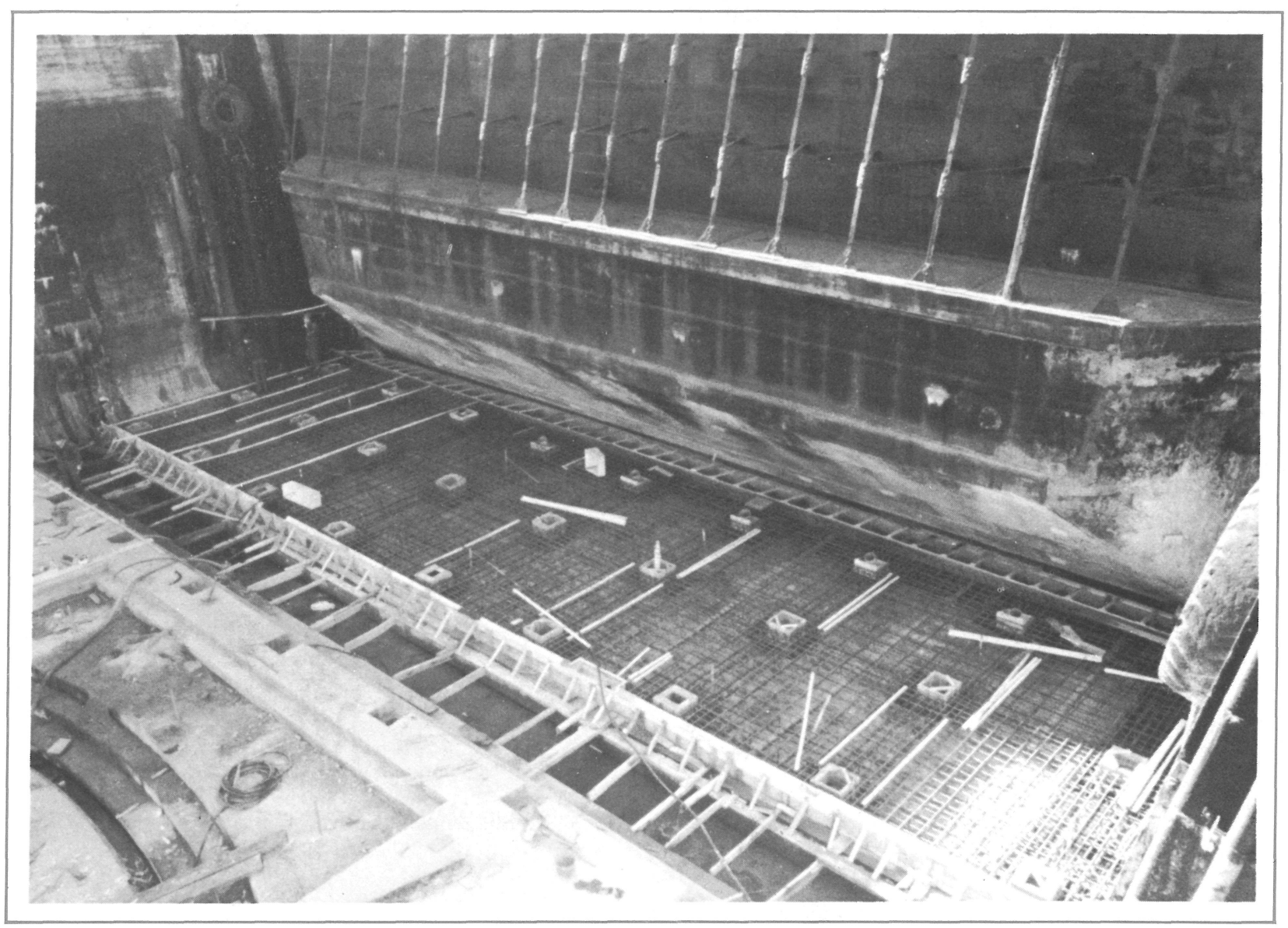

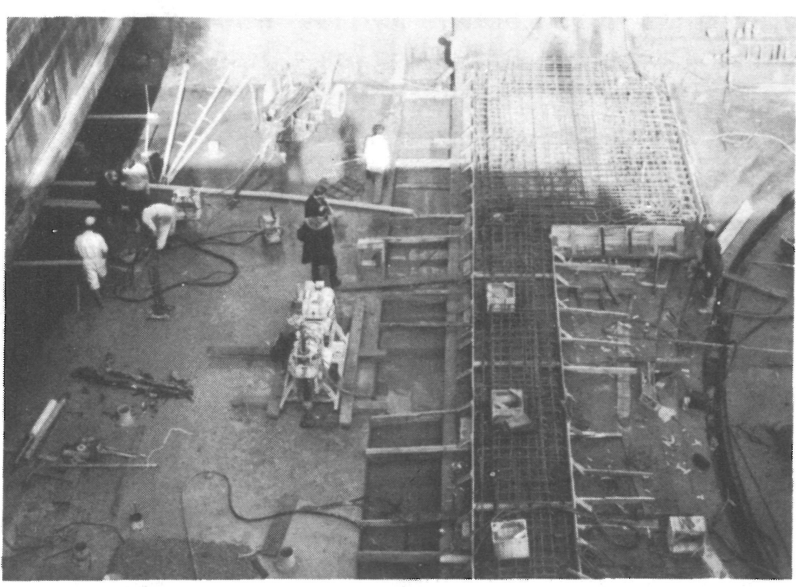

Como medida complementaria, y para evitar una posible acumulación de aguas vagabundas en e trasdós del cajero de babor, se prevé instalar unos pozos drenantes.

El presupuesto de la obra, incluidas otras repacio nes menores (en galerías de servicio, reparación de paramentos, etc.), no supera los $40 \times 10^{6}$ Ptas.

Las obras se espera concluyan en el primer trimestre del año.

Por último, es necesario destacar que esta solución no hubiera sido posible sin la colaboración de los señores Ingenieros de Caminos Monge, de INITEC, y Valdés y Campos, de AUXINI.

Adaptación de Obras y Proyectos:

Alfonso López Marín y José Miguel Frutos. 